\title{
Growth of Homogeneous InGaSb Ternary Alloy Semiconductors on InSb Seed
}

\author{
Noriaki Murakami $^{1)}$, Takuya Hikida ${ }^{1)}$, Akiko Konno ${ }^{1)}$, Kouji Arafune ${ }^{1)}$, \\ Tadanobu Koyama $^{1)}$, Yoshimi Momose ${ }^{1)}$, Tetsuo Ozawa ${ }^{2)}$, Masafumi Miyazawa ${ }^{1)}$, \\ Masashi Kumagawa $^{1)}$ and Yasuhiro Hayakawa ${ }^{1 *}$ \\ ${ }^{1)}$ Research Institute of Electronics, Shizuoka University , Johoku 3-5-1, Naka-ku, \\ Hamamatsu, Shizuoka 432-8011, Japan \\ ${ }^{2)}$ Department of Electrical Engineering, Shizuoka Institute of Science and Technology, \\ Fukuroi, Shizuoka 437-8555, Japan, royhaya@ipc.shizuoka.ac.jp
}

PACS codes: $\quad$ 47.27.Te; 81.10.-h

Keywords: A1. Mass transfer A2. Growth from solution

B1. Gallium compounds B2. Semiconducting III-V materials

Corresponding author; TEL: +81-53-478-1310, FAX: +81-53-478-1310,

E-mail address: royhaya@ipc.shizuoka.ac.jp (Y.Hayakawa)

\begin{abstract}
The paper describes the method to grow homogeneous $\operatorname{In}_{\mathrm{x}} \mathrm{Ga}_{1-\mathrm{x}} \mathrm{Sb}$ ternary alloy bulk crystals. The $\operatorname{In}_{\mathrm{x}} \mathrm{Ga}_{1-\mathrm{x}} \mathrm{Sb}$ crystals were grown under a constant temperature gradient using $\mathrm{InSb}$ (seed)/Te-doped $\mathrm{InSb} / \mathrm{GaSb}$ (feed) samples. The optimum cooling rate to grow homogeneous crystal was given by the product of the temperature gradient and the growth rate. The temperature gradient was estimated from the indium composition profile in the grown crystal. The thermal pulses were applied during the holding process to estimate the growth rate. The respective growth rates were $0.45 \mathrm{~mm} / \mathrm{h}$ and $0.19 \mathrm{~mm} / \mathrm{h}$ for indium compositions of 0.8 and 0.6. The homogeneous $\operatorname{In}_{0.8} \mathrm{Ga}_{0.2} \mathrm{Sb}$ and $\operatorname{In}_{0.6} \mathrm{Ga}_{0.4} \mathrm{Sb}$ crystals were grown by decreasing the temperature with an optimized cooling rate of $0.77^{\circ} \mathrm{C} / \mathrm{h}$ and $0.33^{\circ} \mathrm{C} / \mathrm{h}$, respectively.
\end{abstract}




\section{Introduction}

$\mathrm{In}_{\mathrm{x}} \mathrm{Ga}_{1-\mathrm{x}} \mathrm{Sb}$ is a potential optoelectronic device oriented material and is used to fabricate commercially viable detectors, thermo-photo-voltaic cells, etc. The direct energy gap can be tuned in the range of 1.7-6.8 $\mu \mathrm{m}$ by adjusting the indium composition for infrared applications. Since the lattice constants can be varied in the range of 6.0959-6.4794 $\AA, \operatorname{In}_{\mathrm{x}} \mathrm{Ga}_{1-\mathrm{x}} \mathrm{Sb}$ can be utilized as substrates for growing device quality epilayers.

$\mathrm{In}_{\mathrm{x}} \mathrm{Ga}_{1-\mathrm{x}} \mathrm{Sb}$ bulk crystals grown on earth show difficulty in obtaining high quality crystals. The difficulty arises due to large solidus-liquidus separation in the InSb-GaSb phase diagram [1]. Since the composition in the crystal is different from that in the solution, the rejected solute accumulates in the solution. Due to segregation phenomenon and temperature fluctuation caused by convection, interface breakdown easily occurs and consequently polycrystalline crystals are grown [2]. Since the transportation of the solute is affected by convection, the dissolution and growth processes are strongly influenced by gravity. Therefore, microgravity is a very useful environment to grow high quality and defect free $\operatorname{In}_{\mathrm{x}} \mathrm{Ga}_{1-\mathrm{x}} \mathrm{Sb}$ crystals and to study the effect of transportation of the solute on the solid-liquid interface as the gravity induced negative phenomena can be reduced.

Many experiments have been carried out in microgravity environments such as recoverable satellites and space shuttles. For instance, Witt et al. grew a Te-doped InSb crystal in Skylab and achieved uniform dopant distribution [3]. Kinoshita et al. grew PbSnTe crystals in the SL-J/FMPT mission, and demonstrated that the etch pit density was reduced [4]. Cröll et al. demonstrated that a $\mathrm{Si}$ crystal coated with $\mathrm{SiO}_{2}$ suppressed Marangoni convection and dopant propagation was diffusive in a sounding rocket [5]. Nishinaga et al. and Duffar et al. showed that the quality of GaSb crystals was improved 
under microgravity $[6,7]$. We have carried out several microgravity experiments using a space shuttle, a Chinese recoverable satellite, a drop tower and an aircraft [8-11]. It was clarified that the shape of the growth interface and composition profiles were strongly influenced by gravity. The terrestrial experiments and numerical simulation were done to make clear the effect of gravity on the growth [12-14].

We have been making preliminary experiments for future microgravity experiments in the International Space Station [15]. One of the purpose is to grow homogeneous $\operatorname{In}_{\mathrm{x}} \mathrm{Ga}_{1-\mathrm{x}} \mathrm{Sb}$ ternary bulk crystals of high quality under a constant temperature gradient using a $\mathrm{InSb}$ (seed)/Te-doped $\mathrm{InSb} / \mathrm{GaSb}$ (feed) sandwich structure. $\mathrm{In}_{\mathrm{x}} \mathrm{Ga}_{1-\mathrm{x}} \mathrm{Sb}$ crystal is grown on the InSb seed, while the $\mathrm{GaSb}$ feed is dissolved into In-Ga-Sb solution to supply GaSb component. Since the growth interface shifts to the upper region during growth, the growth temperature has to be decreased with an optimum cooling rate to grow homogenous crystal. Nishijima et al used the multicomponent zone growth method to grow homogeneous InGaAs crystal using a GaAs(seed)/InGaAs/GaAs(feed) sandwich structure. They obtained the optimum cooling rate to grow homogeneous crystals by making several experiments at various cooling rate. [16]. Azuma et al have measured the change of the interface position as a function of time by using a CCD camera for the growth of SiGe They measured the interface position at various ampoule pulling rate and obtained the optimum ampoule pulling rate to keep the interface position constant [17]. In our system, the growth interface can not be measured in situ using a CCD camera because the sample is completely covered with $\mathrm{BN}$ tube for the future microgravity experiment. We have measured the growth rate by introducing thermal pulses in the grown crystal. The temperature gradient is estimated from the Indium composition profile in the grown crystal by using InSb-GaSb binary phase diagram. From the product of the growth rate 
and temperature gradient, the optimum cooling rate to grow $\operatorname{In}_{x} \mathrm{Ga}_{1-\mathrm{x}} \mathrm{Sb}$ homogeneous crystal with a target composition is determined. This method can apply for the growth of the crystal completely covered with the opaque material such as $\mathrm{BN}$ tube.

This paper describes the method to measure the growth rate and to grow homogeneous $\operatorname{In}_{\mathrm{x}} \mathrm{Ga}_{1-\mathrm{x}} \mathrm{Sb}$ bulk crystals on an InSb seed.

\section{Principle of the growth technique}

$\mathrm{In}_{\mathrm{x}} \mathrm{Ga}_{1-\mathrm{x}} \mathrm{Sb}$ ternary bulk crystals is grown under a constant temperature gradient using a $\mathrm{InSb}$ (seed)/Te-doped $\mathrm{InSb} / \mathrm{GaSb}$ (feed) sandwich structure. The principle of the growth technique is as follows.

(1) By increasing the furnace temperature, Te-doped InSb crystal is completely melted and the InSb seed is partially melted. GaSb feed crystal dissolves into In-Sb melt and In-Ga-Sb solution is formed.

(2) The temperature at the solution/feed interface is higher than that at the seed/solution interface, which results GaSb composition at solution/feed interface is higher than that of seed/solution interface. Therefore, the GaSb moves to the seed/solution interface by diffusion and convection due to GaSb composition gradient between solution/feed and seed/solution interface.

(3) The solution near the seed/solution interface becomes supersaturated, which cause spontaneous $\operatorname{In}_{\mathrm{x}} \mathrm{Ga}_{1-\mathrm{x}} \mathrm{Sb}$ crystal growth at seed/solution interface without moving the ampoule. The seed/solution interface slowly moves towards the solution/feed interface due to spontaneous crystal growth. As a result, the Indium composition in the $\mathrm{In}_{\mathrm{x}} \mathrm{Ga}_{1-\mathrm{x}} \mathrm{Sb}$ crystal decreases. In other words the growth temperature increases due to shift of seed/solution interface.

(4) In order to grow homogeneous $\operatorname{In}_{x} \mathrm{Ga}_{1-\mathrm{x}} \mathrm{Sb}$ crystal with a target composition, the 
growth temperature has to be maintained constant. Since the growth temperature increases according to the temperature gradient in the solution, the sample has to be cooled at an optimum value to keep the growth temperature constant.

(5) The cooling rate is given by the product of the temperature gradient in the solution and the growth rate.

(6) The temperature gradient is estimated from the indium composition profile in the crystal. The indium composition profile is converted to the growth temperature profile using a solidus line of the InSb-GaSb binary phase diagram.

(7) The growth rate is measured as a function of longitudinal position by measuring the spacing of the Te impurity striations introduced by thermal pulses. The growth rate is estimated as a function of indium composition.

(8) Since the thermal pulses are introduced at the constant period, the position of the growth interface can be measured as a function of growth time. The Indium composition in the $\mathrm{In}_{\mathrm{x}} \mathrm{Ga}_{1-\mathrm{x}} \mathrm{Sb}$ crystal is measured along the growth length. Therefore, relationship between the indium composition and the growth time (holding time) is estimated.

(9) By keeping the temperature constant for an optimized holding time, the Indium composition in the crystal gradually decreases and reaches a target composition. After that homogeneous InGaSb crystal with the target composition is grown by decreasing the temperature at an optimum cooling rate.

\section{Experimental method}

Fig. 1 shows (a) outside view of an ampoule, (b) an ampoule configuration and (c) the temperature distribution in the furnace. An InSb single crystal was grown in the $<111>$ direction by the Czochralski method to prepare a seed. Te-doped InSb and GaSb feed crystal were polycrystalline. The impurity concentration of the Te-doped InSb was 
$1 \times 10^{21}$ atoms $/ \mathrm{cm}^{3}$. The crystals were shaped into cylindrical form. The lengths of InSb, Te-doped InSb and GaSb were $25 \mathrm{~mm}, 4 \mathrm{~mm}$ and $25 \mathrm{~mm}$, respectively, and the diameter of the crystals was $9 \mathrm{~mm}$. The crystals were polished by alumina abrasive to get mirror surface and then etched in a mixture of $\mathrm{HF}: \mathrm{HNO}_{3}: \mathrm{CH}_{3} \mathrm{COOH}$ taken in the volume ratio $1: 1: 3$ to remove the oxide layer. The crystals were inserted into a BN tube and put into a quartz ampoule. The InSb seed crystal was positioned in such a way that the growth plane became $\{111\} \mathrm{B}$. A BN tube was used to prevent the contact of quartz ampoule and solution. Carbon sheets were adapted to adjust volume change during the dissolution and growth processes. The $\mathrm{BN}$ tube and carbon sheets were baked to about $800^{\circ} \mathrm{C}$ before putting into the quartz ampoule. The ampoule was evacuated to approximately $10^{-4} \mathrm{~Pa}$, and then sealed off. The ampoule was set vertically in a gold coated electric furnace. During growth, the ampoule was not rotated.

We have measured the temperature profiles in the furnace at various reference temperatures and obtained temperature gradient before growth experiment. The temperature gradient in the electric furnace (fig. 1(c)) was fixed as $2.4^{\circ} \mathrm{C} / \mathrm{mm}$. The reference temperature was monitored by a thermocouple set at the interface of $\mathrm{InSb}($ seed $)$ - Te doped InSb interface as shown in fig. 1(b). The temperature in the furnace was changed according to the program, but the temperature gradient was maintained during the experiment. The temperature was raised up to the reference temperature of $530^{\circ} \mathrm{C}$ at a rate of $600^{\circ} \mathrm{C} / \mathrm{h}$ and then kept at that temperature for $100 \mathrm{~h}$. At first, Te-doped InSb crystal was completely melted and the InSb seed was partially melted. After that, GaSb feed crystals started to dissolve into In-Sb melt. The dissolution from the seed crystal continued until the GaSb composition at the seed/solution interface reached an equilibrium value. The thermal pulses were applied during the holding process to obtain the growth rate using a type A sample. The 
temperature was raised by $7.2^{\circ} \mathrm{C}$ by moving the ampoule $3 \mathrm{~mm}$ to a high temperature side. After holding the ampoule for $1 \mathrm{~min}$, it was moved down to the original position. This procedure was repeated with an interval of $5 \mathrm{~h}$. To make clear the introduction of the thermal pulses, thermal pulses were introduced at $20 \mathrm{~h}$ and $21 \mathrm{~h}$. Since the tellurium impurity concentration was modulated by the technique, the impurity striations were introduced in the grown crystal.

The grown crystal was cut longitudinally into two pieces along the growth direction and the surfaces were polished by alumina abrasives. The sample was etched in a solution of $\mathrm{HF}: \mathrm{KMnO}_{4}: \mathrm{CH}_{3} \mathrm{COOH}(1: 1: 1$ vol. ratio) to observe tellurium striations. The indium composition profiles were measured along the growth direction at the center part of the cut surface by Electron Probe Micro Analyzer (EPMA). The detection error is less than 0.002 .

From the position of the striations and the Indium composition profiles, the relationship among the Indium composition, holding time, growth rate and cooling rate was estimated. The homogeneous InGaSb crystals were grown using a type B sample under the estimated growth conditions. During the experiments, the thermal pulses were not introduced.

\section{Result and discussion}

Fig. 2 shows the indium composition profile of the crystal measured along the growth length by EPMA qualitative analysis. In this figure, the initial $\mathrm{InSb}$ (seed)/Te-doped $\mathrm{InSb}$ interface is located at $25 \mathrm{~mm}$ in the longitudinal position. Since the InSb(seed) was partially dissolved, the interface between the $\mathrm{InSb}$ (seed) and InGaSb solution shifted to $8 \mathrm{~mm}$. InGaSb crystal was grown from $8 \mathrm{~mm}$ till $35 \mathrm{~mm}$. So the total growth length was $27 \mathrm{~mm}$. The indium composition gradually decreased and 
reached to 0.4 . This indicates that the growth temperature increased gradually since the growth interface moved to higher temperature zone. The indium composition was converted to the growth temperature using InSb-GaSb binary phase diagram [1]. The calculated temperature gradient was $1.7^{\circ} \mathrm{C} / \mathrm{mm}$ which was smaller than the temperature gradient in the furnace $\left(2.4^{\circ} \mathrm{C} / \mathrm{mm}\right)$. It may be because the thermal conductivity of the solution is higher than that of the solid.

Fig. 3 shows an enlarged photograph of the grown crystal. Two striations were clearly seen in the InGaSb grown crystal. They were formed by the introduction of thermal pulses at $20 \mathrm{~h}$ and $21 \mathrm{~h}$. Fig. 4 shows how the impurity striations are formed in the crystal. Te impurity was charged in the In-Ga-Sb solution by melting the Te-doped InSb. Since the segregation coefficient of Te is less than unity, the amount of the Te impurity in the InGaSb grown crystal was smaller than that of the solution as shown in fig. 4(a). When the thermal pulse was applied, the temperature at the growth interface increased. So, the grown crystal was partially melted and the Te impurity concentration profile was established as shown in fig. 4 (b). After that, the crystal was grown by decreasing the temperature rapidly. Since the effective segregation coefficient approached to unity as the growth rate increased, the Te impurity concentration of the grown crystal was increased as shown in fig. 4(c). It means that the Te impurity concentration of the area grown by introducing thermal pulse was larger than that of the area grown without thermal pulse. By etching the crystal with a solution of HF : $\mathrm{KMnO}_{4}: \mathrm{CH}_{3} \mathrm{COOH}$, the Te impurity striation was formed because the etching rate depended on the Te impurity concentration.

Fig. 5 indicates the growth rate along growth length of the crystal where thermal pulses were introduced. The growth rate gradually decreased from $0.65 \mathrm{~mm} / \mathrm{h}$ at $12 \mathrm{~mm}$ to $0.17 \mathrm{~mm} / \mathrm{h}$ at $28 \mathrm{~mm}$. The growth rate $(\mathrm{V})$ was determined as follows. 


$$
\mathrm{V}=-(\mathrm{f} \partial \mathrm{C} / \partial \mathrm{z}) /\left(\mathrm{C}_{\mathrm{Lo}}-\mathrm{C}_{\mathrm{So}}\right)
$$

Here $\mathrm{C}_{\mathrm{Lo}}$ and $\mathrm{C}_{\mathrm{So}}$ are GaSb concentration in the solution and that in the crystal at the growth interface, respectively. The value $\mathrm{f}$ is transportation rate of $\mathrm{GaSb}$ component from the GaSb feed to the growth interface. Under microgravity, the value $\mathrm{f}$ is given as diffusion coefficient (D) because of the reduction of convection. On the other hand, since solute transportation is affected by convection on earth, the value $\mathrm{f}$ is larger than the diffusion coefficient. The value of $\partial \mathrm{C} / \partial \mathrm{z}$ indicates the composition gradient along the distance $\mathrm{z}$ in the solution.

The InSb composition was changed from 0.9 at $12 \mathrm{~mm}$ to 0.5 at $28 \mathrm{~mm}$, which corresponds to the GaSb composition change from 0.1 to 0.5 at respective positions as shown in fig. 2. From the InSb-GaSb binary phase diagram, the value of $\left(\mathrm{C}_{\mathrm{Lo}}-\mathrm{C}_{\mathrm{So}}\right)$ is found to be varied from 0.086 to 0.32 when the GaSb composition changed from 0.1 to 0.5. From the expression (1), the calculated growth rate decreases 3.7 times by increasing the value of $\left(\mathrm{C}_{\mathrm{Lo}}-\mathrm{C}_{\mathrm{so}}\right)$ from 0.086 to 0.32 . From the experiments, we observed that the growth rate reduction was about 3.8 times from $0.65 \mathrm{~mm} / \mathrm{h}$ to $0.17 \mathrm{~mm} / \mathrm{h}$ when the GaSb composition varied from 0.1 to 0.5 . The experimental result shows good agreement with calculated growth rate.

In order to grow homogeneous crystal, the growth temperature had to be kept constant. Since the growth temperature increased according to the temperature gradient in the solution, the sample has to be cooled at an optimum value to keep the growth temperature constant. The optimum cooling rate was estimated from the temperature gradient $\left(1.7^{\circ} \mathrm{C} / \mathrm{mm}\right)$ and the growth rate. Table. 1 indicates the growth conditions to grow homogeneous crystals. For example, the growth rates were $0.45 \mathrm{~mm} / \mathrm{h}$ and 0.19 
$\mathrm{mm} / \mathrm{h}$ for indium compositions of 0.8 and 0.6 , respectively. Therefore, if the $\mathrm{In}_{0.8} \mathrm{Ga}_{0.2} \mathrm{Sb}$ crystal is to be grown, the temperature is kept for $13.08 \mathrm{~h}$, and then it decreases at a rate of $0.77^{\circ} \mathrm{C} / \mathrm{h}$. If the $\mathrm{In}_{0.6} \mathrm{Ga}_{0.4} \mathrm{Sb}$ crystal is to be grown, the temperature is kept for $42.37 \mathrm{~h}$, and then it decreases at a rate of $0.33^{\circ} \mathrm{C} / \mathrm{h}$.

Fig. 6 (a), (b) shows the indium composition profiles. The homogeneous $\mathrm{In}_{0.8} \mathrm{Ga}_{0.2} \mathrm{Sb}$ and $\mathrm{In}_{0.6} \mathrm{Ga}_{0.4} \mathrm{Sb}$ crystals were grown by decreasing the temperature with an optimum cooling rate of $0.77^{\circ} \mathrm{C} / \mathrm{h}$ and $0.33^{\circ} \mathrm{C} / \mathrm{h}$, respectively. The fluctuation of the Indium composition is less than 0.1 . The length of the single crystals is about $13 \mathrm{~mm}$. Duffar et al grew GaInSb bulk crystals by the Vertical Bridgman technique with alternating magnetic field [18-19]. They demonstrated that alternating magnetic field improved the radial segregation. However the composition profile along the grown axis was not homogeneous due to the axial segregation. Our results indicated that the axial segregation was controlled by applying the optimum growth conditions obtained by thermal pulse technique.

\section{Conclusion}

The preliminary experiments for the microgravity experiment has been carried out to grow homogeneous $\operatorname{In}_{\mathrm{x}} \mathrm{Ga}_{1-\mathrm{x}} \mathrm{Sb}$ ternary bulk crystals under a constant temperature gradient using a InSb(seed)/Te-doped $\mathrm{InSb} / \mathrm{GaSb}$ (feed) sandwich structure. The growth rate was measured from the distance of the Te striations intentionally introduced into the crystal by thermal pulse technique. The respective growth rate of the crystal was 0.45 $\mathrm{mm} / \mathrm{h}$ and $0.19 \mathrm{~mm} / \mathrm{h}$ for indium compositions of 0.8 and 0.6 . The homogeneous $\mathrm{In}_{0.8} \mathrm{Ga}_{0.2} \mathrm{Sb}$ and $\mathrm{In}_{0.6} \mathrm{Ga}_{0.4} \mathrm{Sb}$ crystals were grown by decreasing the temperature with an optimized cooling rate of $0.77^{\circ} \mathrm{C} / \mathrm{h}$ and $0.33^{\circ} \mathrm{C} / \mathrm{h}$, respectively. 


\section{Acknowledgement}

The authors would like to thank Dr.H.Kawai (Shizuoka University) for useful discussion.

\section{References}

[1] G.B. Stringfellow, J.Phys.Chem.Solids 33 (1972) 665.

[2] K.M.Kim, Crystal Growth 44 (1978) 403.

[3] A.F.Witt, H.C.Gatos, M.Lichtensteiger and C.J.Herman, J. Electrochem. Soc. 125 (1978) 1832.

[4] K.Kinosita and T.Yamada, J.Crystal Growth 147 (1995) 91.

[5] A.Cröll, W.Muller and R.Nitsche, J.Crystal Growth 79 (1986) 65.

[6] T.Nishinaga, P.Ge, C.Huo, J.He and T.Nakamura, J.Crystal Growth 174 (1997) 96.

[7] T.Duffar, M.D.Serrano, C.D.Moore, J.Camassel, S.Contreras, P.Dusserre, A.Rivoallant and B.K.Tanner, J.Crystal Growth 192 (1998) 63.

[8] Studies on Crystal Growth under Microgravity, Eds.Y.Hayakawa and Y.Furukawa (Research Signpost, 2005), pp.1-50

[9] K.Okitsu, Y.Hayakawa, T.Yamaguchi, A.Hirata, S.Fujiwara, Y.Okano, N.Imaishi, S.Yoda, T.Oida and M.Kumagawa, Jpn. J. Appl. Phys. 36(1997) 3613.

[10] Y.Hayakawa, Y.Okano, A.Hirata, N.Imaishi, Y.Kumagiri, X.Zhong, X.Xie, B.Yuan, F. Wu, H. Liu, T. Yamaguchi, and M.Kumagawa, J. Crystal Growth 213 (2000) 40.

[11] Y.Hayakawa, K.Balakrishnan, H.Komatsu, N.Murakami, T.Nakamura, T.Koyama, T.Ozawa, Y.Okano, M.Miyazawa, S.Dost, L.H.Dao and M.Kumagawa, J. Cryst.Growth 237-239 (2002) 1831.

[12] N.Murakami, K.Arafune, T.Koyama, M.Kumagawa and Y.Hayakawa, J.Crystal Growth 263 (2004) 320. 
[13] Y.Okano, S.Umemura, Y.Enomoto, Y.Hayakawa, M.Kumagawa, A.Hirata and S.Dost, J.Cryst.Growth 235 (2002) 135.

[14] T.Kimura, A.Arafune, K.Balakrishnan, T.Ozawa, N.Murakami, H.Adachi, Y.Hayakawa and M.Kumagawa, J. Crystal Growth 247 (2003) 291.

[15] N.Murakami., K.Arafune, T.Koyama, M.Kumagawa and Y.Hayakawa, J.Crystal Growth 275 (2005) 433.

[16] Y.Nishijima, K.Nakajima, K.Otsubo and H.Ishikawa, J.Crystal Growth 208 (2000) 171.

[17] Y.Azuma, N.Usami, T.Ujihara, G.Sazaki, Y.Murakami, S.Miyashita, K.Fujiwara and K.Nakajima, J.Crystal Growth 224 (2001) 204.

[18] C.Stelian, T.Duffar, A.Mitric, V.Corregidor, L.C.Alves and N.P.Barradas, J.Crystal Growth 283 (2005) 124.

[19] A.Mitric, T.Duffar, C.Diaz-Guerra, V.Corregidor, L.C.Alves, C.Garnier and G.Vian, J.Crystal Growth 287 (2006) 224.

\section{Figure captions}

Fig. 1. (a) Outside view of an ampoule, (b) an ampoule configuration and (c) the temperature distribution in the furnace.

Fig. 2. Indium composition profile of the crystal measured along the growth length.

Fig. 3. An enlarged photograph of the grown crystal. Two striations were clearly seen.

Fig. 4. Tellurium impurity concentration profiles near the growth interface (a) before, (b) during and (c) after the introduction of thermal pulse.

Fig. 5. Growth rate along length of the crystal where thermal pulses were introduced.

Fig. 6 Indium composition profiles. (a) $\mathrm{In}_{0.8} \mathrm{Ga}_{0.2} \mathrm{Sb}$ and (b) $\mathrm{In}_{0.6} \mathrm{Ga}_{0.4} \mathrm{Sb}$.

Table 1. Growth conditions to grow homogeneous crystals 